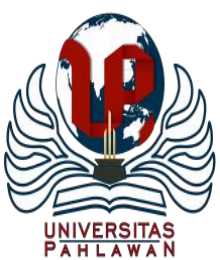

Jurnal Abdidas Volume 1 Nomor 4 Tahun 2020 Halaman 210JURNAL ABDIDAS

Community Development Service on Educational and Health Sciences http://abdidas.org/index.php/abdidas

\title{
Pelatihan Moodle Sebagai Alternatif Pembelajaran Jarak Jauh
}

\author{
Dian Mayasari', Nova Lina Sari Habeahan ${ }^{2}$ \\ Universitas Musamus Merauke, Papua, Indonesia ${ }^{1,2}$ \\ E-mail : mayasari_fkip@unmus.ac.id ${ }^{1}$ habeahan_fkip@unmus.ac.id ${ }^{2}$
}

\begin{abstract}
Abstrak
Penggunaan e-learning diyakini dapat mengatasi keterbatasan perkuliahan di kelas dan menyediakan layanan belajar yang dapat diakses darimana saja dan kapan saja. Kegiatan pelatihan ini diharapkan dapat meningkatkan keterampilan pendidik dalam menggunakan e-learning. Pelatihan ini dilaksanakan selama satu hari di melalui aplikasi Webex dan didampingi oleh Gelora Jatim. Kegiatan dilaksanakan dalam bentuk simulasi, latihan, dan pemecahan masalah. Materi pelatihan adalah pedoman penggunaan e-learning berbasis. Moodle untuk dosen, yang terdiri dari pengaturan mata kuliah, penambahan sumber belajar, membuat grup, memantau progres belajar mahasiswa, dan penggunaan fitur forum, chatting, penugasan, kuis, dan laporan nilai. Kegiatan pelatihan dapat dikatakan berhasil berdasarkan kemampuan peserta dalam memperagakan materi dan dibuktikan dengan hasil karya mereka pada laman e-learning. Peserta merasa pelatihan ini penting karena dapat meningkatkan keterampilan mereka dalam mengelola pembelajaran melalui $e$-learning.
\end{abstract}

Kata kunci: pelatihan, moodle, media pembelajaran

\begin{abstract}
The use of e-learning is believed to overcome the limitations of lectures in the classroom and provide learning services that can be accessed from anywhere and at any time. This training activity is expected to improve the skills of educators in using e-learning. This training was held for one day through the webex application and was accompanied by East Java Gelora. Activities carried out in the form of simulations, exercises, and problem solving. The training material is a guide to the use of Moodle-based e-learning for lecturers, which consists of setting courses, adding learning resources, creating groups, monitoring student learning progress, and using the features of forums, chats, assignments, quizzes, and grades reports. Training activities can be said to be successful based on the ability of participants to demonstrate the material and be proven by their work on the e-learning page. Participants felt the training was important because it could improve their skills in managing learning through e-learning.
\end{abstract}

Keywords: training, moodle, learning media

Copyright (c) 2020 Dian Mayasari, Nova Lina Sari Habeahan

$\triangle$ Corresponding author:

Address : Jalan Kamizaun Mopah Lama Merauke

ISSN 2721-9224 (Media Cetak)

Email: mayasari_fkip@unmus.ac.id

ISSN 2721- 9216 (Media Online)

Phone : 082197800349

DOI: https://doi.org/10.31004/abdidas.v1i4.49 


\section{PENDAHULUAN}

Pemanfaatan teknologi informasi dan komunikasi dalam pembelajaran telah diyakini mampu meningkatkan kualitas pelayanan akademik dan mengatasi keterbatasan pembelajaran di kelas. Menyadari akan hal itu, pimpinan Universitas Islam Kalimantan MAB Banjarmasin untuk mengembangkan sistem $e$ learning menggunakan software Modular ObjectOriented Dynamic Learning Environment (Moodle). E-learning tersebut dipasang pada server universitas dan semua civitas akademika dapat mengaksesnya menggunakan akun sistem informasi akademik.

E-Learning sebagai perangkat elektronik modern memerlukan keterampilan khusus dalam penggunaannya. Dosen-dosen Universitas Islam Kalimantan MAB Banjarmasin sebenarnya sejak lama telah terbiasa dengan penggunaan teknologi informasi dalam pengelolaan pembelajaran. Namun penggunaannya belum tersistem dengan baik dan mereka menggunakannya secara sendirisendiri sesuai dengan kemampuannya. Di antara aplikasi TIK yang digunakan para dosen dalam mengajar adalah: email, blog, media sosial, Youtube, dan Edmodo.

Kebijakan penggunaan e-learning berbasis Moodle yang masih baru dan belum adanya petunjuk dan pelatihan tentang cara menggunakan e-learning tersebut membuat para dosen belum memanfaatkannya untuk mendukung kegiatan pembelajaran. Hasil wawancara penulis dengan dosen-dosen dan pimpinan menunjukkan bahwa mereka memerlukan kegiatan pelatihan tentang penggunaan e-learning berbasis Moodle.
Pelatihan LMS (Learning Management System) Moodle dilakukan agar para pendidik terampil dalam menggunakannya. Di antara bagian e-learning dipahami oleh pendidik adalah: 1) mengatur topik pelajaran, 2) mendesain model pendaftaran siswa, 3) memberikan konten pembelajaran yang menarik, 4) mengkoordinir grup sesuai dengan keperluannya, 5) mengaplikasikan kuis berbasis online, 6) menggunakan bank soal, 7) memakai chat dan forum diskusi,6) melakukan penyimpanan file pribadi, 7) memantau proses belajar siswa, 8) menggunakan fitur web conference, feedback, dan penilaian.

E-learning singkatan electronic learning ialah pembelajaran elektronik yang dilakukan dengan bantuan media online (Batubara, 2016). Elearning ialah proses pembelajaran memakai rangkaian elektronik berfungsi memberitahukan isi materi ajar serta arahan kepada siswa agar memperoleh pengetahuan sesuai dengan keperluannya (Surjono, 2013).

Terdapat dua pendapat mengenai elearning, yaitu: Electronic based e-learning dan Internet based elearning. Electronic based learning ialah tahapan pembelajaran dimana dilakukan berbantuan media elektronik internet, TV, CDROM, radio, dan sebagainya. Maka dari itu, internet merupakan satu contoh bagian e-learning. Internet Based ialah proses pembelajaran tertuju pada pemakaian internet sebagai sarana belajar (Siswa, LoginSurjono, 2016). Maka, e-learning ialah pembelajaran dimana kegiatannya berbantuan perangkat elektronik. Pemakaian teknologi komputer pada e-learning unggul selama 
masa wabah covid 19 sekaligus tantangan untuk pemakaian e-learning. Maka dari itu, dalam kegiatan diperlukan pengetahuan berupa kompetensi pendidik untuk memakai e-learning, mengaplikasikan bahan buku jadi digital, serta didukung komputer, listrik, serta internet yang memadai.

\section{METODE}

Proses Pengabdian Masyarakat dilakukan dalam dua hari melalui model terpadu antara demonstrasi, latihan, serta tanya jawab, demonstrasi. Pemateri menunjukkan tahapan penggunaan bagian di e-learning secara terstruktur serta mengacu pada silabus pelatihan. Tahapan selanjutnya melalui demonstrasi yang diberikan pemateri pada pelatihan e-learning. Selama pelatihan, peserta diberi kesempatan untuk bertanya ketidakpahaman yang dialami saat memakai e-learning.

Materi ajar yang digunakan dalam pelaksanaan Kegiatan Program Pengabdian Kepada Masyarakat ialah sebagai berikut: kegiatan dilakukan dengan penyampaian tujuan dan silabus selama pelatihan e-learning, dilanjutkan melalui demosntrasi serta latihan pengaturan topik materi ajar, tahapan pembelajaran,pendaftaran peserta, pengelompokan siswa, pemeriksaan peningkatan belajar siswa, pengaplikasian isi pembelajaran dengan modul page, file, folder, book, label, URL, serta IMS Content Package, penggunaan bagian forum serta chatting (Muin \& Ulfah, 2012).

Peserta dilatih agar memahami bagian pemberian tugas pada siswa, melalui pengaturan, pemeriksaan, serta penilaian. Selanjutnya peserta diharapkan mampu membuat soal pada bank soal, mengatur pemakaian kuis online, mengelola pertanyaan kuis, serta membagi penilaian $e$ learning pada kegiatan pengabdian pada masyarakat ini ditujukan pada guru sebagai pendidik melalui webinar dengan bantuan aplikasi Webex.

\section{HASIL DAN PEMBAHASAN}

Hasil kegiatan pelatihan e-learning berbasis Moodle untuk pendidik secara nasional sesuai dengan rencana jadwal yang telah disusun telah dihadiri oleh 30 orang sebagai peserta pelatihan.

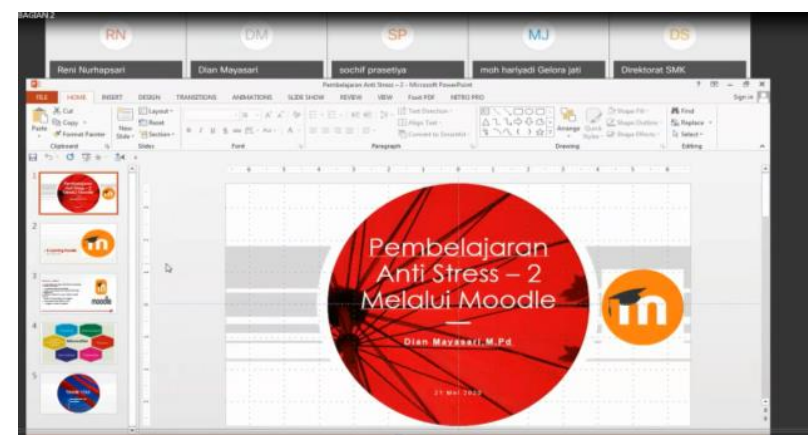

Gambar 1. Proses pelasksanaan pelatiahn online

Adapun materi-materi pokok yang dijelaskan pada kegiatan pelatihan tersebut adalah sebagai berikut: a) metode pendaftaran pada situs e-learning b) membuat mata pelajaran baru dan pengaturan mata kuliah, c) mengelola metode pendaftaran mata kuliah, d) mengelola peserta mata kuliah, e) mengisi konten mata kuliah dengan beragam jenis materi, f) mengelola forum dan chatting, g) membuat kegiatan penugasan, h) mengelola bank soal, i) membuat kegiatan kuis, j). mengelola nilai. 
Semua materi tersebut dibahas dalam bentuk demonstrasi, latihan langsung dan tanya-jawab. Kegiatan pelatihan ini sengaja tidak dimulai dari penyajian teori untuk menghemat waktu pelatihan. Meskipun demikian, pelaksana tetap menghimbau peserta untuk membaca teori tentang e-learning pada buku modul pelatihan (Hamidi et al., n.d.).

Adapun beberapa perlengkapan yang digunakan dalam kegiatan pelatihan ini adalah sebagai berikut: a) laboratorium komputer universitas yang terhubung ke internet. Peserta pelatihan juga diperkenankan untuk membawa dan mnggunakan laptop pribadi pada saat pelatihan berlangsung. b) modul pelatihan e-learning yang disiapkan oleh pelaksana, c) konten pembelajaran elektronik (dibawa oleh peserta).

Penyajian materi dan jawaban terhadap pertanyaan peserta didemonstrasikan pada layar proyektor agar semua peserta dapat menyaksikannya. Pada saat kegiatan pelatihan berlangsung, instruktur menganjurkan agar peserta yang lebih cepat memahami materi membantu peserta yang lambat agar seluruh materi pelatihan dapat diperagan dan dimengerti oleh semua peserta.

Adapun beberapa pertanyaan yang dilontarkan peserta saat kegiatan pelatihan berlangsung adalah sebagai berikut: 1) bagaimana cara mengubah pengaturan kuis? 2) bagaimana cara mengubah nilai kuis? 3) apakah file yang diunggah ke e-learning akan bisa diakses oranglain yang bukan siswa, 4) bagaimana cara menambahkan video dari youtube ke halaman mata kuliah e-learning? 5) bagaimana cara mengaktifkan fitur pemantauan aktivitas mahasiswa pada e-learning?. Semua pertanyaan tersebut telah dijelaskan secara bertahap sambil memperagakannya di hadapan semua peserta pelatihan sehingga semua peserta merasa puas dengan pelatihaan yang telah diberikan. Selama kegiatan, peserta pelatihan tampak aktif dan sangat tertarik dalam menirukan langkah-langkah yang didemonstrasikan instruktur, bertanya, dan meminta bantuan teman yang lebih cepat terampil.

Pelatihan e-learning berbasis Moodle ini dilaksanakan dalam rangkaian kegiatan pengabdian pada masyarakat. Dalam hal ini, pengabdian dilaksanakan diaplikasi Webex di rumah masing masing peserta. Adapun beberapa kendala pelatihan ini dapat dirincikan sebagai berikut. a) Waktu pelaksanaan terlalu singkat untuk materi e-learning yang cukup padat sehingga hasilnya masih kurang maksimal. Pelaksana mengatasinya dengan menyajikan materi pelatihan secara sistematis. b) Sebagian dosen kurang disiplin dan dosen yang memiliki jabatan struktural terkadang meninggalkan ruangan sehingga penyampaian materi kurang efektif.

Untuk mengatasi hal ini, pelaksana harus memilih waktu yang tepat untuk melaksanakan pelatihan e-learning dan meminta pimpinan untuk meliburkan peserta selama kegiatan pelatihan berlangsung. c). Pengetahuan awal sebagian dosen tentang website masih rendah. Sehingga instruktur harus menjelaskan dari awal dengan pelanpelan. Sedangkan sebagian dosen lain cukup cepat dalam memahami materi, pelaksana mengatasinya dengan meminta para peserta yang cepat tanggap untuk membantu peserta yang lambat agar semua 
materi dapat disampaikan dengan efesien. d). Koneksi internet kurang stabil pada siang hari karena civitas akademik banyak yang menggunakan.

\section{SIMPULAN}

Berdasarkan hasil kegiatan pengabdian pada masyarakat yang berupa pelatihan e-learning berbasis Moodle dapat disimpulkan sebagai berikut. a). Pelatihan e-learning berbasis Moodle dapat dilaksanakan dengan sukses, lancar sesuai dengan rencana. b). Kegiatan pelatihan ini memberikan pengetahuan dan keterampilan kepada para dosen tentang cara mengelola pembelajaran menggunakan e-learning Moodle. c). Tingkat pemahaman peserta kegiatan tengan penggunaan e-learning berbasis Moodle meningkat setelah diadakan pelatihan ini. d). Kegiatan pelatihan e-learning memerlukan perencanaan yang cermat dan kerjasama dengan pimpinan universitas.

Kegiatan pelatihan e-learning perlu dilanjutkan secara bertahap kepada operator $e$ learning dan dosen lain yang belum memiliki kesempatan dalam mengikuti pelatihan e-learning. Kegiatan pelatihan e-learning ini juga perlu didukung oleh kegiatan pelatihan yang mengangkat topik tentang cara membuat bahan ajar berbasis TIK (membatik) dengan menggunakan berbagai software. Seperti Lectora Inspire, Quiz Creator, Camtasia, dan lainnya. Pelatihan tersebut juga harus dilaksanakan dengan persiapan dan perencanaan yang lebih cermat dan bekerjasama dengan lembaga terkait.

\section{DAFTAR PUSTAKA}

Batubara, H. H. (2016). Penggunaan Google Form Sebagai Alat Penilaian Kinerja Dosen Di Prodi Pgmi Uniska Muhammad Arsyad Al Banjari. Jurnal Pendidikan Dasar Islam, $8(1)$.

https://www.google.com/intl/id/forms/about/

Hamidi, A. L., Sriyanto, A., Warto, Fakthurrozi, \& Suprisdiantoko. (n.d.). Panduan E-Learning.

Muin, A., \& Ulfah, M. R. (2012). Meningkatkan Hasil Belajar Matematika Siswa dengan Pembelajaran Menggunakan Aplikasi moodle. Pythagoras, 7(1). https://doi.org/10.21831/pg.v7i1.2838

Siswa, LoginSurjono, H. D. (2016). Panduan penggunaan moodle untuk guru SMK Sulawesi Selatan (M. Irhas (ed.); Cetakan Pe). Pt Ebimbel Indonesia.

Surjono, H. D. (2013). Membangun Course ELearning Berbasis Moodle Herman Dwi Surjono. Membangun Course E-Learning Berbasis Moodle, 1-196 